Bull. Mater. Sci., Vol. 4, Number 4, July 1982, pp. 477-481. Printed in India.

\title{
Microstructures, thermal diffusion and decomposition studies in the two phase solution grown mixed crystals of $\mathrm{NaCl}$ and $\mathrm{KCl}$
}

\author{
S R GHADEKAR and B T DESHMUKH \\ Department of Physics, Nagpur University, Nagpur 440 010, India \\ MS received 8 January. 1981 ; revised 12 October 1981
}

\begin{abstract}
Mixed $\mathrm{NaCl}-\mathrm{KCl}$ crystals are grown from water solution. Thermal diffusion, decomposition and microstructures studies by employing the etching technique are reported. It is shown that microstructures consisting of alternate lamellae of $\mathrm{NaCl}$ and $\mathrm{KCl}$ arranged in $\langle 100\rangle$ and $\langle 110\rangle$ directions in the two-phase mixed $\mathrm{NaCl}-\mathrm{KCl}$ crystals observed at room temperature get converted to the one consisting of random mixture of both the phases on finer scale on heating at $300^{\circ} \mathrm{C}$ for $30 \mathrm{hr}$. The dissociated matrix on heating at $600^{\circ} \mathrm{C}$ for $15 \mathrm{hr}$ regains almost all the characteristics of a single crystal transforming the material into single-phase mixed ( $\mathrm{NaK}) \mathrm{Cl}$ crystals. The temperature dependence of the thermal diffusion is discussed.
\end{abstract}

Keywords. Microstructures ; etching ; dislocation pits ; non-dislocation pits.

\section{Introduction}

$\mathrm{X}$-ray, optical and etching studies on the solution grown two-phase mixed $\mathrm{NaCl}$ $\mathrm{KCl}$ crystals (Ingle and Ghadekar 1978, 1979, 1980) have clearly revealed vast structural differences between these solution-grown mixed $\mathrm{NaCl}-\mathrm{KCl}$ and the meltgrown mixed $(\mathrm{NaK}) \mathrm{Cl}$ crystals. The melt-grown mixed crystals have been extensively studied (Burgers and Tichelaar 1953; Wolfson et al 1966; Scheil and Stadelmair 1952 ; Elistratove and Zvinchuk 1960). Some interesting studies on thermal diffusion, decomposition and microstructures are now reported. The two phase $\mathrm{NaCl}-\mathrm{KCl}$ crystals $(\mathrm{NaCl} 61.5 \%$ by wt. and $\mathrm{KCl} 38.5 \%$ by wt.) were grown from solution as reported earlier (Ingle and Ghadekar 1978).

\section{Result and discussion}

In the mixed crystal, owing to the identical crystal structures of the $\mathrm{NaCl}$ and the $\mathrm{KCl}$ and nearly the same ionic radii, the interphase diffusion substituting $\mathrm{Na}^{+}$ions by $\mathrm{K}^{+}$ions and vice versa is expected. Figure 1 shows the $\{001\}$ face of the mixed $\mathrm{NaCl} \cdot \mathrm{KCl}$ crystal etched in ethanol $(99 \%)+\mathrm{PbCl}_{2}$ till saturation for $1 \mathrm{~min}$. (The 
specificity of this etchant to sense the impurity sites of $\mathrm{Na}^{+}$ions has already been established by Ingle and Ghadekar (1980). The figure shows impurity pits of $\mathrm{Na}^{+}$ ions at the non-dislocation sites. On heating the crystal at $300^{\circ} \mathrm{C}$ for $7.30 \mathrm{hr}$ or for 22.6 hr at the same temperature, the density of thelimpurity pits is found to increase correspondingly. This suggests that the diffusion of $\mathrm{Na}^{+}$ions in the lattice is temperature-dependent. On continuous heating for more than $22.6 \mathrm{hr}$ the decomposition centres are found to nucleate on $\{00 \mathrm{I}\}$ surface in the regions with high defect density implying that the lattice defects facilitate decomposition. Figure 2 shows the microphotograph of the $\{001\}$ face of the crystal obtained after heating for $30 \mathrm{hr}$ and subsequently etched in ethanol $+\mathrm{PbCl}_{2}$ for $1 \mathrm{~min}$ as usual. This etchant in this case produces no pitting on the surface but the normal dissolution rate of this etchant is found suitable to attack $\mathrm{KCl}$ regions efficiently; however the etchant produces no dissolution on the $\mathrm{NaCl}$ regions enabling identification of the participating phases. Thus, the regions deeply etched (dark) mark the $\mathrm{KCl}$ phase and the lightly etched (whitish) regions mark the $\mathrm{NaCl}$ phase. If such $\{001\}$ face is etched in glacial acetic acid (99\%) for $3 \mathrm{~min}$ (Ingle and Ghadekar 1978), no dislocation pits characteristic of single crystal nature are produced. This clearly indicates that the crystal has lost the single crystal nature, the crystal matrix being dissociated with loss in coherency of the phases. In contrast, on heating the crystal at $300^{\circ} \mathrm{C}$ for not more than $22.6 \mathrm{hr}$ the matrix remains undissociated and the constituent phases remain in tact.

The microstructures of figure 2 show that the participating phases are distributed randomly on finer scale. These microstructures are remarkably distinguished from the type generally observed at RT consisting of the patterns of alternate lamellae of $\mathrm{NaCl}$ and $\mathrm{KCl}$ very much similar to the eutectic one (Ingle and Ghadekar 1978). Thus microstructures with lameller patterns heated as above get converted to the type with random mixture of the phases.

On heating the mixed solid at temperature above the miscibility gap such as $600^{\circ} \mathrm{C}$ for 14 or $15 \mathrm{hrs}$, the randomly distributed phases start reorientations transforming the material into a single phase solid solution $(\mathrm{NaK}) \mathrm{Cl}$. This is clearly seen in figure 3 which is the microphotograph of the $\{001\}$ surface of figure 2 obtained after heating as explained above. The surface comparatively becomes smoother and thermal pits are produced because of evaporation at atomic steps. Such a surface if etched in the etchants (Ingle and Ghadekar 1978) such as glacial acetic acid $(99 \%)$ or ethanol $+\mathrm{PbCl}_{2}$, produces square dislocation pits on $\{001\}$ face characteristic of a single crystal nature.

\section{Conclusion}

The lamellar microstructures consisting of alternate lamellae of $\mathrm{NaCl}$ and $\mathrm{KCl}$ arranged in $\langle 100\rangle$ and $\langle 110\rangle$ directions are found to transform on heating at $300^{\circ} \mathrm{C}$ for more than $22.6 \mathrm{hr}$ to the type consisting of random mixture of both the phases on finer scale. The dissociated matrix on heating at $600^{\circ} \mathrm{C}$ for $15 \mathrm{hr}$ get converted to a regular matrix, the matrix of a single phase mixed ( $\mathrm{NaK}) \mathrm{Cl}$ single crystal. 

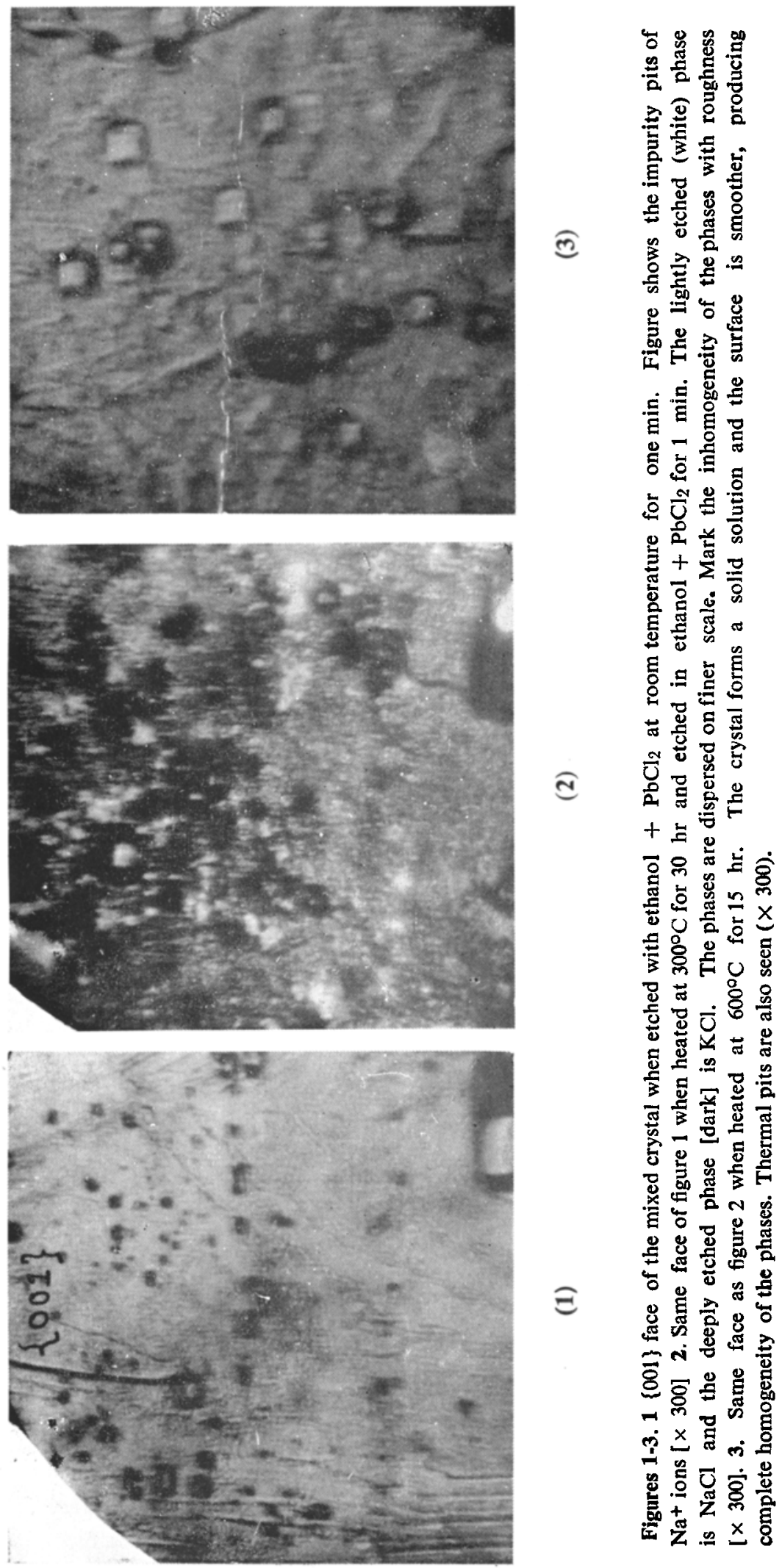

苍号恣 莡至 总造 초용 些岩总 点穿鬲 도 을 के . 훙 문 E $+\frac{\pi}{\Sigma}=$ 훙 氖 놀 范的 จे चु 可要曹

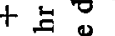
웧 혼 요월

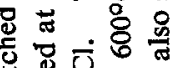
造击 里旅

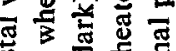
응 品 药范密 造总总苔

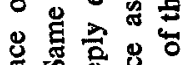

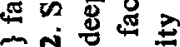
융류 × 웡 高范品品 


\section{References}

Burgers W G and Ticheiaar G W 1953 Proc. K. Ned. Akad. Wet. 8 57-73

Elistratov A M and Zivinchuk R A 1960 Sov. Phys. Solid State (Engl. Trans.) 2111

Ingle S G and Ghadekar S R 1978 J. Phys. D11 913

Ingle S G and Ghadekar S R 1979 Indian Sci. Congr. Assoc., Phys. Sec. Abstract No. 21

Ingle S G and Ghadekar S R 1980 Indian J. Phys. (In Press)

Scheil $E$ and Stadelmair H 1952 Z. Metallkd. 43277

Wolfson R G, Kobes W and Fine M E 1966 J. Appl. Phys. 37704 